2022 • Winter - Kış • Volume - Cilt: 13 • Issue - Sayı: 48

\title{
Gutenberg Galaksisinden Meta Evrenine: Üçüncü Kuşak İnternet, Web 3.0
}

\author{
İbrahim Sena ARVAS, İstanbul Üniversitesi, Gazetecilik Bölümü, Doç. Dr., \\ ibrahimarvas@istanbul.edu.tr, iD 0000-0002-5558-6913
} pratiklerinin de birer birer dijitalleşmesine neden olmuştur. Sosyalleşmenin dijitalleşmesi ise özellikle ikinci kuşak internet olarak anılan Web 2.0 sonrası hiz kazanmıştır. Gerek bireysel gerekse toplumsal yaşam, geçmişte matbaa ve televizyon gibi kitle iletişim araçlarının icadı ile dönüşümlere uğramıştır. Bu dönüşümler günümüzde internet teknolojisinin sürekli güncellenen yapısı içerisinde dinamik bir hal almıştır. Bu durum neredeyse tüm internet kullaniclarının bir sonraki dönüşümle ilgili heyecan ve merak duymalarına neden olmaktadır. Bu günlerde internetin Web 2.0'dan sonraki kuşağının insanların hayatına nasıl etki edeceği gündemden düşmemektedir. Özellikle blokzinciri üzerinde inşa edilen kripto para birimlerinin yaygınlaşması, internetin yaşayacağı muhtemel dönüşüm konusunda ip uçlarn içermektedir. Blokzinciri teknolojisinin internetin yeni kuşağı olma ihtimali giderek artmaktadır. Ayrıca temelinde açık dünya aksiyon oyunları mantığı olan meta evreni projelerinin, Covid-19 pandemisiyle birlikte ciddi bir işlevsellik kazanması da beklenmektedir. Bu doğrultuda hazırlanan meta evreni projelerine her geçen gün bir yenisi eklenmektedir. Özellikle blokzinciri teknolojisi üzerinde geliştirilen NFT'ler ile meta evreni projeleri arasındaki ilişki, internetin yeni kuşağı olan Web 3.0 ile ilgili öngörüleri ciddi manada şekillendirmektedir. Tüm bunlarm yanı sira mevcut teknoloji şirketleri ve sosyal medya platformlarının, söz konusu gelişmeler karşısındaki hazırlikları ise bir var oluş mücadelesine düşecek gibi görünmektedir.

Anahtar : $\quad$ Web 3.0, Semantik ağ, Blokzinciri, Meta evreni, NFT

Kelimeler

\section{From the Gutenberg Galaxy to the Metaverse: Third Generation Internet, Web 3.0}

ABSTRACT

The rapid development of internet technology has led to the digitization of daily practices of real life day by day. The digitization of socialization has gained momentum especially after Web 2.0, which is called the second generation internet. Both individual and social life have undergone transformations in the past with the invention of mass media such as the printing press and television. Today, these transformations have become dynamic within the constantly updated structure of internet technology. This situation causes almost all internet users to feel excited and curious about the next transformation. Nowadays, how the internet after Web 2.0 will affect people's lives remains on the agenda. In particular, the spread of cryptocurrencies built on the blockchain gives clues about the possible 
transformation of the internet. The possibility that the blockchain technology will be the next generation of the internet is increasing. In addition, metaverse projects, which are based on the logic of open world action games, are expected to gain important functionality together with the Covid-19 pandemic. Every day, a new metaverse project is added to the current ones prepared accordingly. In particular, the relationship between NFTs (Non-Fungible Tokens) developed on blockchain technology and metaverse projects significantly shapes the predictions about Web 3.0, the new generation of the internet. In addition to all these, the preparations of existing technology companies and social media platforms related to these developments seem to become a struggle for existence.

Keywords : $\quad$ Web 3.0, Semantic web, Blockchain, Metaverse, NFT

\section{EXTENDEN ABSTRACT}

The common points of Web 1.0, where the internet allows only one-sided information flow and people are only consumers, and Web 2.0, an interactive internet structure referred to as 'user-generated content' in the literature, in which users are active, is that the existence of both depends on at least one central server. Tim Berners Lee expressed his concerns that most of the aforementioned developments have existed since the early days of the Web, but have come into use over time, so the term Web 2.0 should be used in a more meaningful and filled-in way (The First Web 2.0 Conference, 2004). This change in internet technology is a soft evolution, so to speak. Because, as Lee emphasized, Web 2.0 emerged with the discovery of the features provided by the previous generation.

The Semantic Web, on the other hand, not only connects documents but also recognizes the meaning of the information in those documents. In other words, the Semantic Web aims to extract the existing Web from a set of interconnected, semantically isolated data islands and transform it into huge personal information repositories, processing and access databases (Berners-Lee, Hendler, \& Lasilla, 2001, p. 1-3).

The Semantic Web is an evolving extension of the current web that aims to enable these softwares to easily find and share data and combine information so that web contents can be expressed not only in natural languages but also in a way that can be understood, interpreted, and used by related software (Ünal, 2015, p. 39). The basis of the Semantic Web concept that Lee mentions is an internet system in which scattered piles of data are transformed into meaningful data islands. What is mentioned at this point is the clustering of disconnected data in a meaningful way and the adaption of these meanings for the access, storage, and internetspecific similar reflexes of the relevant receivers in a certain order.

This semantic evolution, which continues towards the 3rd generation internet, also contains clues about the future. It is possible to encounter these clues in Tim Berners-Lee's ideals. Lee began Chapter 12 of his book, titled "Mind to Mind," with his dream of a future 
that also includes the Semantic web. Lee's dream has two parts and contains signs beyond the Semantic web. These signs can be traced to the building blocks of the road to Web 3.0 today. The second part of Lee's dream mentions collaborations between computers. Besides, the title of Chapter 12, which introduces the dream, is also "mind to mind." From this perspective, it can be said that Lee envisioned a decentralized, peer-to-peer structure for the Semantic Web. Perhaps a hidden bibliographical link can be found between the "peer-to-peer network" (Nakamoto, 2008, p. 8) work of Nakamoto, the inventor of the blockchain and Bitcoin, and the "mind-to-mind" dream of Lee, the inventor of the World Wide Web. Thus, it will be appropriate to evaluate the developments related to Web 3.0 in this context.

The semantic web will continue to evolve with descriptive and meaningful software. However, this evolution is not sufficient for the Semantic web to be called Web 3.0 on its own. The development of blockchain-based applications has made the first steps of a great revolution on the internet palpable. In this case, it seems that the Semantic web will be one of the tools of this new revolution, but as a definition, it cannot go beyond Web 2.0+ (plus). However, when Lee's ideal is combined with Nakamoto's invention, it would make more sense to talk about a new internet generation.

Satoshi Nakamoto registered the domain name bitcoin.org on August 18, 2008, created a website at this address and published the article titled "Bitcoin: A Peer-to-Peer Electronic Cash System" (Nakamoto, 2008). As the title of this article suggests, a peer-to-peer network is indicated as the basis of Bitcoin. The same connection, as a network, is referred to as a "peerto-peer network" (Nakamoto, 2008, p. 1) on the first page of the article. As the subject is elaborated in the article, it is understood that the said network will consist of a chain of interconnected blocks. Later, this network was called the blockchain. In that article, the words block and chain were not used contiguously as blockchain even once. The fact that blockchain technology is open source, that different blockchain infrastructures can be established and operated reliably, that it cannot be regulated and audited by any central authority (Blockchain Technology Terminology Study, 2019, p. 8-9) has made many people working on internet technology think that this technology can be used not only for asset transfer but also for data transfer and storage. Due to its nature, the possibility of the blockchain hosting the entire internet is one of the most talked-about topics in the context of Web 3.0 lately. The internet running on the blockchain network will undoubtedly result in much larger algorithms, datasets, and information being analyzed than it is now. When the Semantic web tools mentioned above are integrated with this technology and developed on the blockchain network, Web 3.0 will offer people unimaginable possibilities. Thus, Web 3.0 with blockchain and Semantic software is expected to transform the internet into a much more transparent and decentralized structure than it is today. In today's internet technology, data ownership is at the discretion of cellular data providers. Web 3.0 needs to return data to its rightful owners 
and return the internet to its original form, i.e., direct communication from one computer to another computer, leaving networks under the control of others.

Although Web 3.0 has not been fully defined yet, built on current developments, the most consistent expectation of this new internet generation refers to a future equipped with decentralized peer-to-peer, IoT, and virtual reality running on the blockchain network. Another pillar of Web 3.0 is undoubtedly the concept of Metaverse, one of the most popular concepts of today, which is expected to be built on the blockchain for its functionality.

Today, there are many metaverse platforms built to consolidate multiple online spaces into a 3D platform. These platforms are developed in a way to offer users a wide range of activities, including communicating in 3D (possibly with virtual reality equipment), participating in artistic activities such as concerts and movies, playing games together, and organizing meetings and training programs. It is seen that most of the metaverse projects tested on the Web 2.0 network today try to create unique virtual environments. However, some of them copy the maps of the real world exactly and sell these copies by dividing them into parcels in 3D. These applications, which are against the concept of meta, are seen as cheap virtual copies of the real world. Such practices, which contradict real-world principles of international law such as property rights, borders, and national security, are unlikely to exist in the future. Behind such efforts is the goal of the commodity universe's cryptocurrency projects to find more investors.

The developments in the metaverse have pushed technology companies such as Google and Apple to produce projects and prepare ambitious plans. Also, in October 2021, Mark Zuckerberg, the owner of Facebook, announced that they changed the name to "Meta" (BBC, October 2021). It seems that technology companies and social media platforms have started competing with each other to take part in the metaverse trend. However, the seizure of the metaverse by crypto money projects, as mentioned above, pushed the social media actors of Web 2.0 to act faster. In this way, valid currencies in the metaverses of crypto projects are cryptocurrencies that they produce on the blockchain. The migration of metaverse projects into the blockchain network in the future will make these projects decentralized. In this case, there is also the possibility of existing big technology companies and social media platforms losing hundreds of billions of dollars in revenue. Besides all these, there is an organic link between metaverse projects and NFTs (Non-Fungible Tokens). NFT is a technology that helps determine the owner and authenticity of digitally produced or shared content. NFT is a new type of crypto asset, a blockchain product used to create and securely store contents of artistic value in the digital environment. NFT was born out of the desire and need to create property rights on digital content (Tilegal.com, May 2021). The need to display the NFTs that people buy in exchange for cryptocurrencies causes a necessary relationship between the commodity universe and NFTs, hence cryptocurrencies. 


\section{GİRIŞ}

Fütürist özelliklerini göz önünde bulundurduğumuzda Marshall McLuhan'ın zamanında küresel köy tanımını yaparken interneti ön görmüş olabilme ihtimali her zaman tartışma konusu olmuştur. Gutenberg Galaksisi adlı eserini iletişim devrimleriyle insanların ve toplumsal hayatın nasıl evrimleştiği üzerine bina etmiştir. Bu eserde McLuhan (1962, s. 145, 164); matbaa sonrası basılı kitapların el yazmalarının aksine insanlar için özel taşınabilir enstrümanlar haline dönüştügünü böylece insanları yalnızlaştırdığını savunur. Bu bakış açısına göre, el yazması eserler çoğaltma güçlügü nedeniyle okuyan ve dinleyenlerin iletişimi tabanlı bir toplumsallaşma inşa etmiş, akabinde matbaayla içerikler bireysel erişilebilirliğe kavuşmuş, yaygınlaşmış ve insanları yalnızlaştırmıştır. $\mathrm{Bu}$ durumdan hareketle, hiyerogliflerden internete kadar iletişim teknolojilerindeki tüm gelişmeler insani ve dolayısıyla toplumsal yaşam pratiklerinde köklü evrimlere neden olmuşlardır, denilebilir. McLuhan'ın bakış açısı güncellenecek olursa; internet teknolojisinin yaygınlaşmasının ve gelişmesinin de toplumsal yaşama benzer bir etkisi olmuştur. Örneğin radyo 1920'lerde evlere girmeye başladığında, radyo alıcısının etrafında toplanmış tek taraflı bir enformasyon akış sürecini topluca tüketen ve çoğu zaman ilgili enformasyon konusunda birbirleriyle iletişim kuran insanlara rastlamak mümkünken, radyo alıcılarının yaygınlaşması, küçülmesi ve taşınabilir olmaları sonucu insanlar yine fiziken yalnızlaşmaya başlamışlardır. Aynı örneği televizyon için vermek de mümkündür. Dolayısıyla sözü edilen kitle iletişim araçları yaygınlaştıkları ölçüde enformasyonun bireysel tüketimine neden olmuşlardır. Ancak bilgisayar teknolojisi diğerlerinin aksine kişisel bir araç olarak insanların hayatına girmiştir. 1950'lerin sonunda büyük bilimsel bilgisayarların piyasadaki varlıkları kesin olarak bilinmektedir. Ancak dönemin büyük bilimsel bilgisayar üreticilerinin, küçük rekabetçi bilgisayar üretmeye yeterli kaynak ayıramamaları, irili ufaklı birçok şirketin küçük bilgisayarları piyasaya sürmesine neden olmuştur. Böylelikle 1960'lar PC (Personal Computer) olarak bilinen kişisel bilgisayar evrimin başlangıcı olmuştur (Allan, 2001, s. 1/16). İnternet teknolojisinin özellikle 1990'ların sonunda bilgisayarlarla bütünleşmesiyle birlikte bu aygıtın bir kitle iletişim aracı olarak kabul edilmesi sağlanmıştır. Gelinen noktada bilgisayarların internetten bağımsız olarak düşünülememesinin temel nedeni; bilgisayarlar icat edildiğinden bugüne tüm çabanın onları birbirine bağlamak olduğu gerçeğidir.

İnternetle birlikte kişisel bilgisayarların iletişim araçları haline dönüşmelerinin ardından yaşanan teknolojik gelişmelerin hemen hemen hepsi internetin geçirdiği evrim bağlamında gerçekleşmiştir. İnternetin evrimine bakıldığında önceleri birinci kuşak internet olarak anılan web 1.0 teknolojisi kapsamında sadece tek taraflı içerik üretimine imkan veren ve deyim yerindeyse kullanıcıyla düz çizgisel bir iletişim kuran internet siteleri, ikinci kuşak internet olarak anılan web 2.0 teknolojisiyle birlikte yeni bir işlev kazanmıştır. Web 2.0 ile kullanıcıların aktif olduğu etkileşimli dairesel iletişim biçimi, interneti insanlar için vazgeçilmez bir haberleşme aracına dönüştürmüştür (Arvas, 2018, s. 452). İnternet 
teknolojisinde yaşanan bu evrim de yukarıda söz edildiği gibi gerek insani gerekse toplumsal yaşam pratikleri üzerinde doğrudan etkili olmuş, dünyaya ait birçok değerin dijitalleşmesinin önünü açmıştır. Gelinen noktada dijitalleşmedeki hız öyle bir hal almıştır ki; McLuhan'ın Gutenberg Galaksisi metaforuyla günümüz teknolojilerinde sıkça söz edilen meta evreni (metaverse) arasında ortalama bir insan ömrü kadar bile zaman farkı bulunmamaktadır.

Yukarıda sözü edilen gelişmelerden hareketle bu çalışmanın temel problemi de internet teknolojisinde dolayısıyla dijitalleşmede yaşanan bu hızlı değişimin yakın gelecekte insanları nasıl bir dünya ile karşı karşıya bırakacağını araştırmaktır. Bu doğrultuda çalışmanın hipotezi; 3. kuşak internetin yani Web 3.0'ın, öngörülen merkeziyetsiz yapısı, blokzinciri ağ ve meta evreniyle ilişkisi bağlamında teknolojik bir devrim olduğudur. Bu hipotez literatür taraması ve bu tarama sonrası elde edilen verilerin karşılaştırılması ile sınanmıştır. Bu bağlamda Web 3.0 teknolojisinin temelini oluşturması beklenen blokzinciri ağı, bu ağ üzerinde var olması beklenen teknolojiler, çalışmanın 2. ana başlı̆̆ında ele alınmış belli başlı konulardır. Ayrıca 2. ana başlığın en önemli içeriği de Web 3.0'ın muhtemel yapısının bu başlık altında tartışılmasıdır. Düne kadar birçok internet araştırmacısının Web 3.0'ı yalnızca Semantik Web olarak tanımlamasının günümüzde yeterli olmadığı varsayımı, ikinci başlığın en önemli konusudur. Çalışmanın 3. ana başlığı altında ise söz konusu blokzinciri ağının ev sahipliğinde inşa edilmesi beklenen yeni internet düzeninin gündeme getirdiği meta evreni kavramı tanımlanmaya çalışılmıştır. Bu başlığın bir başka önemli yanı da mevcut köklü internet teknolojisi şirketleri ile sosyal medya devlerinin söz konusu gelişmeler karşısında yaptıkları hamleleri içermesidir. Çalışmanın sonuç bölümünde ise Web 3.0'ın gündelik yaşam pratikleri ve toplumsal hayat üzerindeki muhtemel etkilerine ilişkin değerlendirmeler yer almaktadır.

Son olarak bu çalışma yazılım ve mühendislik terminolojisinden olabildiğince uzak durmayı, konuyu bir sosyal bilimler ilgilisinin anlayabileceği şekilde ele almayı amaçlamaktadır. Bu nedenle teknik detaylar olabildiğince sade bir şekilde ele alınmaya çalışılmış ve asıl ağırlığın sosyolojik bağlama verilmesine gayret edilmiştir.

\section{2. İNTERNETINN 3 KUŞAĞI}

Yukarıda da söz edildiği gibi internetin sadece tek taraflı enformasyon akışına imkan tanıdığı ve insanların sadece tüketici konumunda olduğu Web 1.0 ile literatüre 'user generated content' olarak geçen, kullanıcıların aktif olduğu etkileşimli internet yapısı Web 2.0'ın ortak noktaları her ikisinin de varlığının merkezi en az bir sunucuya bağlı olmasıdır. Buradaki evrim, içerik üreticilerinin web sitelerinin sahiplerinden ibaret olmaktan çıkması, tüketicilerin de ilgili sitelere içerik üretmelerine imkan tanınmasıdır. Yalnızca okuma (read only) dönemi olarak da anılan Web 1.0'ın enstrümanları; kişisel ya da kurumsal internet siteleri, çevirmeli (dial-up) modemler, veri indirme (download), tek yönlü akıştır. Web 1.0'ın tüm özelliklerini barındıran Web 2.0'ın enstrümanları ise özetle; bloglar, mikro bloglar ve sosyal medya, sayısal 
abone hattı (DSL), kablosuz bağlantı (wireless), veri yükleme (upload), uzak depolama (cloud computing) gibi birçok etkileşimli özelliktir.

Web 2.0 terimi ilk olarak Darc DiNucci (1999, s. 32) Print isimli basılı bir dergide 1999 yılında ortaya atılmıştır. DiNucci'nin fütürist bakış açısıyla kaleme aldığı makalede Web 2.0'ın internet sitelerinin içeriklerinin öncelikle kullanıcılar tarafından oluşturulduğu ve paylaşıldığ bir ortamdan söz edilmiştir. Kavramın yıllar sonra tekrar gündeme gelerek popüler olması ise 5-7 Ekim 2004'te San Francisco'da düzenlenen Birinci Web 2.0 başlıklı konferansta Tim O'Reilly ve Dale Dougherty tarafından tanımlanması sonucu mümkün olmuştur (O'Reilly, 2005). Söz konusu konferansa World Wide Web’in mucidi Tim Berners Lee de katılmış ve sözü edilen gelişmelerinin çoğunun Web'in ilk günlerinden beri var olduğunu ancak zamanla kullanılmaya başlandığını bu nedenle Web 2.0 teriminin daha fazla içinin doldurularak anlamlı bir şekilde kullanılması gerektiğine dair endişelerini dile getirmiştir (The First Web 2.0 Conference, 2004).

Internet teknolojisindeki bu değişim, deyim yerindeyse yumuşak bir evrimden ibarettir. Çünkü yukarıda Lee'nin de altını çizdiği gibi Web 2.0 aslında kendisinden önceki kuşağın imkan tanıdığı özelliklerin keşfedilmesi ile ortaya çıkmıştır. Hatta birçok bilim insanı henüz Web 1.0'ın egemen olduğu zamanlarda internetle ilgili cümleler kuraralarken Web 2.0'ın özelliklerinden söz eden tanımlamalar yapmışlardır. Örneğin Donna L. Hoffman 2000 yılında interneti insanların gündelik hayatlarında sanal bir devrim olarak tanımlarken, bireylerin anında değiş tokuşta aktif olarak katkı sağlamasından ve geri bildirim döngülerinin etkileşimli bir hal almasından söz etmiştir (Hoffman, 2000, s. 3). Hoffman'ın Web 1.0'in son demlerinde kurduğu bu cümlelerin Web 2.0'1 işaret ettiği açıcça görülmektedir.

\subsection{Semantik Web}

İnternetin mucidi olarak bilinen Tim Berners-Lee'nin halen görev yaptığ1 Massachusetts Institute of Technology'nin resmi internet adresindeki kişisel sayfasında, kendisinin 1989 yılında küresel bilgi paylaşımı için internet tabanlı bir hiper ortam girişimi olan World Wide Web'i (www) icat ettiği yazmaktadır (Tim Berners-Lee, 2021). Türkçesi dünyayı saran internet olarak kabul edilen World Wide Web'in henüz tek taraflı enformasyon akışına olanak tanıdığı yani Web 1.0 olduğu yıllarda, Semantik Web terimini ortaya atan kişi de Tim Berners-Lee'den başkası değildir. Lee günümüzdeki interneti 21 yıl önce Semantik Web kavramıyla idealize etmiştir. Dolayısıyla Türkçesi Anlamsal A $\breve{g}$ olan Semantik Web kavramı World Wide Web'in mucidi Tim Berners-Lee'nin parlak zekasının ürünüdür. Semantik Web'in arkasındaki fikir, yalnızca belgeleri birbirine bağlayan değil, aynı zamanda bu belgelerdeki bilgilerin anlamını da tanıyan bir ağ örmektir. Başka bir deyişle Semantik Web; mevcut Web'i bir dizi birbirine bağlı, anlamsal olarak izole edilmiş veri adalarından çıkartıp, devasa kişisel bilgi depolarına, işleme ve erişim veri tabanına dönüştürmektir (Berners-Lee, Hendler \& Lasilla, 2001, s. 1-3). 
Semantik Web, web içeriklerinin sadece doğal dillerde değil, aynı zamanda ilgili yazılımlar tarafından anlaşılabilir, yorumlanabilir ve kullanılabilir bir biçimde ifade edilebileceği, böylece bu yazılımların veriyi kolayca bulmasını, paylaşmasını ve bilgiyi birleştirmesini sağlamayı amaçlayan, gelişen bir internet eklentisidir (Ünal, 2015, s.39). Lee'nin söz ettiği Semantik Web kavramının temelinde dağınık veri yığınlarının anlamlı veri adalarına dönüştürüldügü bir internet düzeni yatmaktadır. Bu noktada birbirinden kopuk verilerin anlamlı bir biçimde kümelenmesi ve bu anlamların yine belli bir düzen içerisinde ilgili alıcıların erişimine, depolamasına ve bunun gibi internete özgü reflekslerine uygun hale gelmesinden söz edilmektedir.

İnsanlar interneti kullanarak “araba” sözcügünün Hintçe karşılığını bulabilir, kütüphanelerden bir kitabı ayırtabilir veya aradıkları DVD'nin en ucuza satıldı ̆̆ yeri bulup satın alabilirler. Fakat bir bilgisayar bu işleri insan yönlendirmesi olmadan tamamlayamaz çünkü web sayfaları makinaların değil, insanların okuması için yapılmıştır. Semantik web; bilgisayarlar tarafından anlaşılabilir ve böylece bilgiyi bulma, paylaşma ve birleştirme işlerindeki can sıkıcı işleri, tabiri caizse angaryaları otomatikleştirebilir (Ünal, 2015, s.39). Semantik web düne kadar birçok internet araştırmacısına göre Web'in yeni hali yani Web 3.0 olarak tanımlanmaktaydı. Bu tanımlamanın nedenlerinden birisi, Web 2.0'ın kendisinden önceki internet kuşağının sahip olduğu teknolojiyi daha verimli kullanmaktan öteye geçemediği halde onun bir üst sürümü olarak anılması olabilir. Bu noktadan hareketle söz konusu araştırmacılar yine Web 2.0'ın özünde olan özelliklerle geliştirilmiş bir anlamsal ağ Web 3.0 olarak tanımlamışlardır.

Semantik webin yukarıda söz edilen özelliklerine bakıldığında bugün kullandığımız internetin içerisinde var olduğunu ve her geçen gün de hacmini artırdığ1 görülmektedir. Örneğin akademisyenlerin performanslarını değerlendirmekte kullanılan atıf sayıları bağlamında konuya bakmak gerekirse, söz konusu sayıların bulunmasında Semantik webin unsurlarının varlığı açıkça görülmektedir. Semantik web bilginin kataloglaşmasına, çeşitli verilerin birbirleriyle ilişkilendirilmesi sonucu bibliyografik veriler üretmeye yarar. $\mathrm{Bu}$ özellikleri bağlamında akademik makaleler arasındaki ilişkilerden dolayısıyla verilerden anlamlı kümeler oluşturarak gelişmiş dizinlerin var olmasını sağlar. Ancak bu ilişkilerin var olması Semantik webin evriminin bittiği anlamına gelmemektedir. Aynı örnekten devam edilecek olursa, günümüzde akademisyenlerin aldıkları atıfların günümüzde sadece nicelik bağlamında değerlendirildiği ve bu değerlendirme sonucu performans kriterlerinin belirlendiği hatta teşvik ödeneklerinin de bu bağlamda hesaplandığı bilinmektedir. Oysa akademik yaşamda negatif atıf diye bilinen bir atıf biçimi de bulunmaktadır. Negatif atıfta, atıf yapılan eserin içerik ya da yöntem bakımından yanlışları veya eksilerinden söz edilir. Buna rağmen yanlışlanan ya da eleştirilen makale bu atıfla yazarına atıf puanı kazandırmış olur. Niceliğe dayalı bu çarpık ölçme ve değerlendirme sistemi ancak Semantik web 
unsurlarının gelişmesiyle giderilebilecektir. Yakın bir gelecekte makaleler arasında anlamsal ağlar daha detaylı bir biçimde kurulacak ve atıfların negatif ya da pozitif olarak ayrışması da sağlanacaktır.

3. Kuşak internete doğru süregelen bu anlamsal evrim temelinde gelecekle ilgili ipuçları da barındırmaktadır. Bu ipuçlarına da yine Tim Berners-Lee'nin ideallerinde rastlamak mümkündür. Lee kitabının "Mind to Mind” (Zihinden zihine) başlıklı 12. bölümüne Semantik webi de barındıran gelecek hayaliyle başlamıştır (Berners-Lee \& Fischetti, 2000, s. 157-158):

"İnternet için iki bölümden oluşan bir hayalim var. İlk bölümde internetin insanlar arasındaki iş birliği için daha güçlü bir araç haline gelmesi var. Hayalim bilginin insanların sadece göz attığı değil ayrıca yarattığı bir şey olması, her zaman ve herkes için anında ve sezgisel bir erişime sahip olmasıdır. Ayrıca insandan insana iletişimdeki bu hayalin, dolaşımdaki bilgiyle elektronik olarak etkileşim kurmanın büyüklüğü ne olursa olsun tüm gruplar için de tıpkı bireysel olduğu kadar kolay olmasıdır. Hayalimin ikinci bölümünde ise bu etkileşim ve iş birlikleri bilgisayarlara kadar uzanıyor. Bilgisayarların içerikler, linkler ve insanlarla aradaki bütün işlemler gibi internetteki tüm verileri analiz etme yeteneğine sahip olacak bir internetin hayali bu. Henüz oluşmamış olsa da bu hayali mümkün kılan bir Semantik web ortaya çıtığında, ticaretin günlük mekanizmaları bürokrasi ve günlük hayatlarımızı birbirleri ile konuşan makinalar tarafından değerlendirilecek."

Lee'nin bu iki bölümden oluşan hayali yukarıda sözü edilen Semantik webin ötesinde işaretler barındırmaktadır. Bu işaretlerde günümüzde Web 3.0'a doğru giden yolun yapı taşlarının izlerini görmek mümkündür. Lee'nin hayalinin ikinci bölümünde bilgisayarların birbirleriyle kuracakları iş birliklerinden söz edilmektedir. Bunun yanı sıra hayalin yer aldığ 12. bölümün başlığının da "mind to mind" olduğu görülmektedir. Bu noktadan hareketle Lee'nin Semantik Web için merkeziyetsiz, eşler arası (peer to peer) bir yapı idealize ettiği akla gelmektedir. Belki de blokzincirinin ve Bitcoin'in mucidi Nakamoto'nun “peer to peer network" (Nakamoto, 2008, s.8) çalışması ile World Wide Web'in mucidi Lee'nin "mind to mind" hayali arasında gizli bibliyografik bir bağ kurulabilir. Nitekim Web 3.0 ile ilgili gelişmeleri bu bağlamın üzerinde ele almanın tutarlı olacağı izlenimi oluşmaktadır.

Yukarıdaki örneklerden de hareketle Semantik webin; Web 2.0'ın imkan verdiği meta datalarla, herhangi bir internet sitesi tarafından bilgisayarlara bırakılan ve çerezler (cookies) olarak anılan dosyalarla veya yeni geliştirilen/geliştirilecek olan tanımlayıcı ve anlamlandırıcı yazılımlarla evrimini sürdüreceği ortadadır. Ancak bu evrimin Semantik webin tek başına Web 3.0 olarak anılması için yeterli bir evrim olmadığı da ortadadır. Blokzinciri tabanlı uygulamaların gelişmesi internette yaşanacak büyük bir devrimin ilk adımlarını hissedilebilir kılmıştır. Bu durumda Semantik webin mutlaka bu yeni devrimin enstrümanlarından biri olacağı ancak tanımlama olarak deyim yerindeyse Web 2.0+ (plus) ötesine geçemeyeceği 
görülmektedir. Ancak Lee'nin ideali Nakamoto'nun buluşu ile birleşince yeni bir internet kuşağından söz etmek daha anlamlı olacaktır.

\subsection{Blokzinciri ve Web 3.0}

Bloklar üzerinde verilerin değiştirilemez bir şekilde saklanmış olduğu devamlı olarak büyüyen merkeziyetsiz veri tabanını ifade eder. Verilerin yer aldığı şifrelenmiş veri kümesi olan "blok" ile bu blokların hemen önceki bloklara şifrelenmiş imzalar yoluyla bir araya gelmesini ifade eden "zincir" ifadelerinin birleştirilmesiyle ortaya çıkmıştır (Blokzinciri Teknolojisi Terminoloji Çalışması, 2019, s. 13). Bir başka deyişle Blokzinciri ismini her bir bloğun bir önceki bloğa kriptografik özet değeri ile bağlı olduğu zincir yapısından almaktadır (Akleylek \& Seyhan, 2018, s.27). Blokzincirinin temeli, gerçek kimliği henüz belli olmayan Satoshi Nakamoto takma adlı kişi ya da kişilerin 2007 yılında merkeziyetsiz bir şekilde kullanıcılar arasında aracısız değer transferi sağlamak için deneysel olarak kod yazma çalışması yapmalarıyla atılmıştır. Bu denemenin ardından Satoshi Nakamoto 18 Ağustos 2008 tarihinde bitcoin.org alan adını alarak bu adreste bir internet sitesi oluşturmuş ve burada "Bitcoin: Eşler Arası Elektronik Nakit Sistemi" (Nakamoto, 2008) başlıklı makaleyi yayınlamıştır. Bu makalenin sadece başlı̆̆ından bile anlaşılacağı gibi Bitcoin' in temelinde eşler arası yani "peer to peer" bir bağlantıya işaret edilmiştir. Aynı bağlantı bir ağ olarak makalenin birinci sayfasında "peer to peer network" (Nakamoto, 2008, s. 1) olarak anılmıştır. Makalede konu detaylandıkça söz konusu ağın birbirine bağlı blokların oluşturduğu bir zincirden meydana geleceği anlaşılmaktadır. Daha sonra bu ağ blokzinciri (blockchain) olarak anılmıştır. Söz konusu makalenin içerisinde block ve chain kelimeleri bir kez bile bitişik olarak “blockchain” şeklinde kullanılmamıştır.

Satoshi Nakamoto, güvensiz ve potansiyel olarak hileli, dağıtık bir işlemci ağında, bilgi paylaşımının nasıl olacağı problemine, merkezi bir otorite kullanmadan, yeni bir çözüm önermiştir. Satoshi Nakamoto'nun Nisan 2011'de ortalıktan kaybolmasına rağmen, sistem tamamen şeffaf ve matematik prensipleri çerçevesinde çalışmaya devam etmektedir (Çarkacıŏlu, 2016, s.15).

Blokzincirinin çalışma prensibi, Akleylek ve Seyhan'ın (2018, s. 28-29) adımlara ayırdığı sırada Bitcoin yerine veri yazılarak şu şekilde açıklanabilir:

1- A, B'ye veri transfer ister.

2- A işlem mesajını ağa yayınlar. (Bu dünya çapında bir ağdır.)

3- Diğer düğümler, blokzincirinin yerel kopyalarını kullanarak A'nın veriyi transfer etme hakkına bakar ve işlemin A tarafından onaylanıp onaylanmadığını kontrol eder.

4- Doğrulama işlemi gerçekleştirildikten sonra işlem bloğa eklenir. 
5- Yeni blok işlem listesini, onun başlığını, önceki blok başlığının özetini ve içerilen işlemlerin özetini içerir.

6- Madencilik süreci başlar. (Madencilik, yeni bir blok zincir elde etmek ve zincirdeki işlemler için matematiksel doğrulama gerektirmesi işidir. Madenciler işlemleri toplarlar ve bunları bir blokta birleştirirler. Madenciler yeni bloğu tüm bloğa yayması ve bu işlemi blokzincirine kaydetmesi sonucu "şu an için" kripto parayla ödüllendirilirler.)

7- Düğümler matematiksel bir problemi çözmek için bir yarışma başlatır.

8- Yeni blok, blokzincirine eklenir.

9- Her bir düğüm sahip olduğu yerel kopyayı günceller.

10- B veriyi alır.

Blokzinciri teknolojisinin verilerin güvenli bir biçimde saklanması ve herkes tarafından şüpheye yer vermeyecek şekilde doğrulanabilmesi için merkezi bir otoriteye bağlı olmadan çalışabilecek şekilde kurgulanmış yapısı dünya çapında büyük bir ilgiyle karşılanmıştır. Blokzinciri teknolojisinin anılan olumlu özellikleri, bu teknolojinin gün geçtikçe daha fazla sektörde veya ülkede yoğun bir şekilde kullanılarak sayısız uygulamanın ya da projenin doğmasını sağlamış ve hayatın bazı alanlarını kolaylaştırmaya başlamıştır. Blokzinciri teknolojisinin açık kaynaklı olması farklı blokzinciri altyapılarının kurgulanmasına ve güvenilir bir şekilde çalışması ise çeşitli, hiçbir merkezi otorite tarafından düzenlenip denetlenemez olması (Blokzinciri Teknolojisi Terminoloji Çalışması, 2019, s. 8-9), internet teknolojisi üzerine çalışan birçok kişinin aklına bu teknolojinin sadece varlık transferi için değil veri transferi ve depolanması için de kullanılabileceğini getirmiştir.

$\mathrm{Bu}$ özellikleri nedeniyle, bir teknoloji olarak blokzinciri, finansal işlemlere temel teşkil etme amacının ötesinde dikkat çekmiştir. Blokzinciri dağıtılmış bulut depolama, akıllı mülk, nesnelerin interneti, tedarik zinciri yönetimi, sağlık, mülkiyet ve telif dağıtımı ve merkezi olmayan özerk organizasyonlar da dahil olmak için birçok alanda kullanılmaya uygundur (Wüst \& Gervais, 2018, s.45). Blokzincirinin kayıt defterleri, verileri kriptografik kanitlarla birbirine bağlı kronolojik bir sıralama olarak organize eden bloklar halinde kaydetmekte ve depolamaktadır (Binance Academy, Aralık 2018). Blokzincirinin geçmişe yönelik verilerin silinmesine imkan vermemesi dışarıdan gelecek saldırılarda sistem günlüklerinin silinmesinin mümkün olmaması onu veri depolama gerektiren tüm alanlar için işlevsel kılmaktadır. Blokzincirinin üzerinde; hisse senetleri, gelir/gider verileri, emekli aylıkları, sigorta poliçeleri, seçmen bilgileri, patentlerin yanı sıra adli sicil, nüfus, noter, gayrimenkul, pasaport, kredi, sözleşme kayıtları gibi sayısız alanda sınırsız veri güvenle saklanabilir.

Blokzincirinin avantajları şu şekilde sıralanabilir (Gatteschi vd., 2018, s.68):

- Zincir üzerindeki veriler eşler arasında kaydedildiği için veri kaybı önlenir ve bu veriler erişime açık ve şeffaftır. 
- Dijital imza ve doğrulamalar nedeniyle taraflar arasında güven sağlanır.

- Dünya çağında erişime açık bir veri havuzu oluşur ve potansiyel olarak herkes bu verilere erişebilir, ekleme yapabilir.

- Şeffaflık garantidir. Herkes sadece işlemlerin son duruma değil tüm geçmişine erişebilir.

- Geçmiş veriler silinemez ve değiştirilemez.

- Akıllı sözleşmeler ile faaliyetler otomatikleştirilebilir. Otomasyon sağlanır ve zaman kaybının önüne geçilir.

Blokzincirinin şu ana kadar tespit edilen dezavantajları ise;

- Ağdaki verilerin kopyalarının eşler arasında kaydedilmesi, geçmişin değiştirilmez ve sürekli erişime açık olması unutulma hakkı, veri mahremiyeti gibi konularda sıkıntılar yaşanmasına neden olabilir.

- Blokzincirindeki verilerin uzlaşma protokolü temelli olması, yeni bir blokzinciri elde etmek ve zincirdeki işlemler için matematiksel doğrulama gerektirmesi (madencilik) oldukça pahalı bilgisayar donanımlarına olan ihtiyacı artırmakta ve ciddi manada enerji sarfiyatına neden olmaktadır. Hatta bu ağ üzerindeki, en popüler varlık olan Bitcoin'in Cambridge Üniversitesi tarafından yapılan bir analize göre yıllık olarak Arjantin'in tamamından daha fazla elektrik tükettiği belirlenmiştir (BBC, Şubat 2021).

Blokzincirinin yapısı itibariyle tüm internete ev sahipliği yapma ihtimali son zamanlarda Web 3.0 bağlamında en çok konuşulan konulardandır. İnternetin blokzinciri ağ üzerinde çalışması hiç şüphesiz şu ankinden çok daha büyük algoritmalara, veri kümelerine ve analiz edilecek bilgilere kavuşmasına neden olur. Yukarıda sözü edilen Semantik webin enstrümanları bu teknolojiyle entegre edilerek blokzinciri ağı üzerinde geliştirilince Web 3.0 insanlara hayal edilemeyecek imkanlar sağlayacaktır. Nitekim blokzinciri ve Semantik yazılımlarla Web 3.0'ın interneti günümüzdekinden çok daha şeffaf ve merkeziyetsiz bir hale dönüştürmesi beklenmektedir. Bugün kullanılan internet teknolojisinde veri sahipliği hücresel veri sağlayıcıların inisiyatifindedir. Web 3.0' 1 n veriyi gerçek sahiplerine iade etmesi, internetin başkalarının yönetiminde olan ağlardan çıkarak aslına, yani bilgisayardan doğrudan başka bir bilgisayara haberleşme, haline geri döndürmesi gerekmektedir. 
Tablo.1: Web 1.0, 2.0, ve 3.0'ın Özellikleri (Grayscale Research, 2021, s. 5).

\begin{tabular}{|l|c|c|c|}
\cline { 2 - 4 } \multicolumn{1}{c|}{} & Web 1.0 & Web 2.0 & Web 3.0 \\
\hline Etkileşim & Okuma & Okuma - Yazma & $\begin{array}{c}\text { Okuma - Yazma - } \\
\text { Sahip Olma }\end{array}$ \\
\hline Araç & Statik Metin & İnteraktif İçerik & Sanal Ekonomiler \\
\hline Organizasyon & Şirketler & Platformlar & Ağlar \\
\hline Altyapi & Kişisel Bilgisayarlar & Bulut ve Mobil & Blokzinciri Bulutu \\
\hline Kontrol & Merkeziyetsiz & Merkezi & Merkeziyetsiz \\
\hline
\end{tabular}

Yukarıdaki tablodan da anlaşılacağı gibi Web 3.0 henüz tam olarak tanımlanmasa da mevcut gelişmeler üzerine inşa edilen en tutarlı beklenti, bu yeni internet kuşağının blokzinciri ağı üzerinde işleyen, merkeziyetsiz eşler arası çalışan, nesnelerin interneti ve sanal gerçeklikle donatılmış bir geleceği ifade etmektedir. Web 3.0'ın bir diğer ayak sesi de kuşkusuz blokzinciri üzerine inşa edilmesi beklenen günümüzün en popüler kavramlarından biri meta evreni kavramidir.

\section{EVREN ÖTESİ}

İlk kez Neal Stephenson tarafından 1992 yılında Snow Crash adlı bir romanda kullanılan Metaverse tabiri (Stephenson, 1992, s.22) ilk kullanılışında da günümüzdeki anlamı işaret etmiştir. Romanda; “Arkasında ona ulaşabilmenin yolları yazıyor. Bir telefon numarası ve Metaverse içinde yer alan bir adres." şeklinde bir cümle bulunmaktadır. Romanda Metaverse kavramı, kullanıcıların dijital avatarlar aracılığıyla etkileşime girdiği devasa bir sanal fiziksel dünya olarak tanımlanmıştır.

Metaverse kavramı; evren (universe) ile ötesi (meta) kelimelerinin birleşiminden oluşmaktadır. Türkçe'ye birebir çeviri karşılığı evrenin ötesi olsa da bu 'Meta evreni' tabiri olarak literatüre yerleşmeye başlamıştır. Geride bıraktığımız 30 yıl boyunca internet teknolojisinin sürekli gelişerek gerçek hayatın pratiklerini kendi bünyesine katmaya devam ettiği görülmektedir. Meta evreni de bu gelişmelerin günümüzdeki en güncel halkasıdır. Kavramın içerisindeki 'evren' kelimesi söz konusu yapının farklı dünyalardan oluşacağını işaret etmektedir. Bu nedenle günümüzde piyasada olan ve meta evreni projesi olduğunu iddia eden uygulamaların, sadece bu evrenin içerisinde kendisine yer bulmaya çalışan denemelerden ibaret olduğu tespitini yapmak gerekmektedir.

Meta evreni geçmişte bilgisayar oyunu oynayan insanlar için çok da uzak bir tabir değildir. Geçmişte Grand Theft Auto III (2001), Second Life (2003) ve Call of Duty (2003) gibi henüz 3 boyutlu (3D) ya da sanal gerçeklik (Virtual Reality, VR) ekipmanları piyasa çıkmadan insanların oynadığı açık dünya aksiyon oyunları (open world action games) günümüzdeki meta evreni projelerinin ilham kaynaklarıdır. 
Ayrıca yukarıda sıralanan oyunlardan sonra gelişen internet teknolojisi, mobil cihazlar ve Web 2.0'ın özellikleri, çevrimiçi çoklu oyunculu (multiplayer) canlı oynanabilen yeni oyunlar geliştirilmiştir. Google Play ve App Store işletim sistemlerine özgü elektronik medya dağıtım/satış platformlarından söz konusu oyunlara çevrimiçi satın alma özellikleri eklenmiştir. Böylelikle insanlar oyunlarda yönettikleri karakterlerine diğer oyuncuların karakterlerine çeşitli üstünlükler sağlamak amacıyla sanal ekipmanlar satın almaya başlamışlardır. İnsanların gerçek dünyadaki paralarını oyunlardaki sanal karakterlerinin rekabetinde harcamaları bu şekilde gerçekleşmektedir.

Günümüzde pek çok oyuncu paralarını ve saatlerini Web 2.0 kapalı kurumsal meta evreni dünyalarında dijital zenginlik oluşturmak için harcamaktadır. Sorun şu ki, çoğu oyun geliştiricisi oyuncuların oyun içi yatırımlarından ve çabalarını gerçek dünyada nakde çevirmelerine izin vermemektedir. Geliştiriciler, oyuncuların diğer oyuncularla oyun içi varlık takası yapmasını yasaklamakta ve oyuncuların oyun içi zenginliklerini gerçek ekonomiye aktaramaması için bu dünyaları kapalı tutmaktadırlar. Web 3.0 açık blokzinciri ağları, Web 2.0 platformları tarafından bu sanal dünyalara uygulanan sermaye kontrollerini ortadan kaldırarak bu sorunu çözmektedir. Bu yeni paradigma, kullanıcıların benzersiz dijital varlıklarına (Non-Fungible Tokens, NFT) sahip olmalarını, bunları oyun içinde başkalarıyla takas etmelerini ve diğer dijital deneyimlere taşımalarını sağlayarak paraya dönüştürülebilen tamamen yeni bir serbest pazar yaratmaktadır. Yaratıcı ekonominin bu evrimi "kazanmak için oyna" (Play to Earn) olarak tanımlanmaktadır (Grayscale Research, 2021, s. 8).

Temeli oyunlara dayanan meta evrenine özellikle Covid-19 pandemisi ile birlikte insanların fiziksel hayatlarının hemen hemen tüm alanlarında dijital dönüşümü gerçekleştirmek gibi bir rol yüklenmeye başlanmıştır. Meta evrende, Web 3.0'ın ve Semantik webin vizyonları da yer almaktadır. Artırılmış Gerçeklik, 5G ve yapay zeka gibi gelişen teknolojilerin rotasında yer alan meta evreni göründüğ̈ kadar fütürist değildir.

Günümüzde birden fazla çevrimiçi alanı 3 boyutlu bir platformda toparlamak için inşa edilen birçok meta evreni platformu bulunmaktadır. Bu platformlar, kullanıcıların 3 boyutlu olarak (imkanlar dahilinde sanal gerçeklik ekipmanlarıyla) iletişim kurmalarına, konser, sinema gibi sanatsal aktivitelere katılmalarına, birlikte oyun oynamalarına, toplantılar ve eğitimler düzenlemelerine kadar çok çeşitli eylemlere imkan tanıyacak şekilde geliştirilmektedirler. Günümüzde Web 2.0 ağı üzerinde denemeleri yapılan meta evreni projelerinin çoğunun özgün sanal ortamlar oluşturmaya çalıştı̆̆ görülmektedir. Ancak bunlardan bazılarının gerçek dünyanın haritalarını birebir kopyaladıkları, bu kopyaları 3 boyutlu bir şekilde parsellere ayırarak satışa çıkardıkları görülmektedir. Meta kavramına aykırı olan bu uygulamalar gerçek dünyanın ucuz sanal kopyaları gibi görülmektedir. Gerçek dünyadaki mülkiyet hakkı, ülke sınırları ve milli güvenlik gibi uluslararası hukukun prensipleri ile çelişen bu tür denemelerin gelecekte var olmaları pek mümkün değildir. Bu tip 
çabaların arkasında, meta evreninin kripto para birimi projelerinin daha fazla yatırımcı bulmak amacı yatmaktadır.

Meta evreni gelişmeleri Google ve Apple gibi teknoloji şirketlerini projeler üretmeye iddialı planlar hazırlamaya itmiştir. Ayrıca 2021 yılının Ekim ayında Mark Zuckerberg sahibi olduğu Facebook'un adını "Meta" olarak değiştirdiklerini açıklamıştır (BBC, Ekim 2021). Anlaşılan o ki teknoloji şirketleri ve sosyal medya platformları meta evreni akımında yer almak için birbirleri ile yarışmaya başlamışlardır. Ancak söz konusu meta evreninin diğer bir taraftan yukarıda söz edildiği gibi kripto para projeleri tarafından ele alınması, Web 2.0'ın sosyal medya aktörlerini daha hızlı davranmaya itmiştir. Nitekim kripto projelerinin meta evrenlerinde geçerli para birimleri blokzinciri üzerinde kendilerine özgü ürettikleri kripto paralardır. Meta evreni projelerinin ileride blokzinciri ağı üzerine taşınması söz konusu projeleri merkeziyetsiz bir yapıya büründürmesi söz konusu olabilir. Bu durumda mevcut büyük teknoloji şirketlerinin ve sosyal medya platformlarının yüz milyarlarca dolarlık gelirlerinden olma ihtimalleri de öngörülebilir gelişmeler arasındadır.

Tüm bunların yanı sıra meta evreni projeleri ile NFT'ler (Non-Fungible Tokens) arasında organik bir bağ bulunmaktadır. "Değişimi mümkün olmayan kripto varlık” olarak Türkçe'ye çevrilen NFT, dijital ortamda üretilen ya da paylaşılan içeriklerin sahibini ve orijinalliğini belirlemeye yarayan teknolojidir. NFT, dijital ortamda, özellikle sanatsal değeri olan içerikler üretmek ve bunları güvenli şekilde saklamak için kullanılan bir blokzinciri ürünüdür ve yeni bir tür kripto varlıktır. NFT, dijital ortamdaki içerikler üzerinde de mülkiyet hakkı yaratma isteği ve ihtiyacından doğmuştur (Tilegal, Mayıs 2021). İnsanların kripto paralar karşılığında satın aldıkları NFT'leri sergileme ihtiyacı meta evreni ile NFT'ler dolayısıyla kripto paralar arasında zorunlu bir birlikteliğe neden olmaktadır.

Dünyanın en büyük 100 şirketi sıralamasında Mart 2021 verisine göre 839 Milyar Dolar market değeri ile 7. sırada yer alan ve yeni adı Meta olan Facebook (Ross, Haziran 2021), yukarıda sözü edilen meta evreni ve kripto para ilişkisine de blokzinciri üzerinde inşa ettiği kripto para birimi projesi Facebook Libra ile çözüm aramıştır. Şirket, Haziran 2019 da kendi bünyesinde geliştirmeye çalıştı̆̆ kripto para biriminin bir yıldan kısa bir sürede piyasa sürülmesi amaçlamıştı. Ancak Amerika Birleşik Devletleri makamları Libra'nın Amerikan Doları'nı tehdit edebileceği, siber suçlara yol açabileceği, kullanıcı gizliliğini tehlikeye atabileceği ve şirkete kontrol edilmesi zor bir güç kazandıracağ yaklaşmışlardır. Ardından proje şirket tarafından revize edilmiş ve adı Novi olarak değiştirilmiştir. Fakat söz konusu çalışmalar da yeterli olmamış ve Aralık 2020'de Diem olarak yeniden adlandırılmışsa da henüz hayata geçememiştir, sınırlı olarak ilerlemektedir (Duffy, 2022). Şirketin bu çabaları meta evreni oluşturmak için blokzinciri üzerine inşa edilmiş bir kripto para biriminin gerekliliğini gözler önüne sermiştir. Görülmektedir ki günümüzde kripto para ve blokzinciri ağı olmadan meta evreni içerisinde bir dünya kurmak neredeyse mümkün değildir. 


\section{SONUÇ}

Gutenberg Galaksisi'nde matbaanın yalnızlaştırdığı insanların meta evrenindeki sosyalleşme arayışları, iletişim teknolojilerinin yaşam üzerindeki etkilerini net bir şekilde özetlemektedir. İnsanın benliğini inşa etme sürecinde diğer insanlara duyduğu ihtiyacın bir benzeri de bilgisayar teknolojilerinde yaşanmaktadır. Bilgisayarlar da insanlar gibi bir ağa bağlı olmadıkları sürece gelişimlerini tamamlayamamaktadırlar. Bilgisayarın birbirleriyle iletişimi konusu günümüzde insanların dünya ve diğer insanlarla olan bağını belirleyen yegane unsur haline gelmiş durumdadır.

$\mathrm{Bu}$ bağlamda internetin geçirdiği evrimler insanların tüm yaşam pratikleri üzerinde son derece etkili olmaktadır. İnternet her geçen gün insanları dünyadaki gelişmelere bağlama işlevini güçlendirmektedir. Ancak internet teknolojisinde son zamanlarda gündeme gelen gelişmeler, yakın bir gelecekte insanı gerçek dünya yerine kendi bünyesinde oluşturduğu dünyalara bağlamaya başlayacağını işaret etmektedir.

Birinci kuşak internet olarak anılan Web 1.0'1n tek yönlü iletişim ortamı kısa sürede yerini Web 2.0'ın etkileşimli dairesel iletişimine bırakmıştır. Araştırmacıların birçoğu Web 2.0 üzerinde geliştirilen Semantik webin internetin yeni kuşağı olacağını ileri sürmüşlerdir. Ancak 2008 yılında paranın, aracı olmadan transferi arayışının sonucu olarak ortaya çıkan blokzinciri ağı, internetin tüm geçmiş kuşaklarını unutturacak gelişmelerin habercisi olmuştur. Bilgisayarların birbirine bağlanması ve veri transferi için bir merkezin varlığına olan ihtiyacı ortadan kaldıran blokzinciri ağı, beraberinde internetin yeni enstrümanlarının doğuşuna da zemin hazırlamıştır.

Günümüzde bu enstrümanların en popülerlerinin başında meta evreni gelmektedir. Gerek NFT'ler gerek kripto paralar ile olan ilişkisi nedeniyle meta evreni, konvansiyonel sosyal medya platformları için vakit kaybedilmeden içinde yer alınması gereken bir evren olmaya doğru gelişmektedir. Zira günümüzde Dünya borsalarını domine eden teknoloji şirketlerinin meta evreni gelişmesini kaçırması, onun merkeziyetsiz internet temelinde şekillenmesine izin vermeleri, tüm bu şirketlerin gelecekte yok olma tehlikesi ile karşı karşıya kalmaları ihtimalini ortaya çıartmaktadır. Bu nedenle meta evrenine giriş ile başlayan süreç kısa sürede Web 3.0 bağlamında şekillenmesi muhtemel tüm gelişmeleri yakından takip etmeyi ve deyim yerinde ise içlerinden ses getirenlere (NFT örneğinde olduğu gibi) hızlıca el atmayı gerektirecektir. Bunun yanı sıra şu sıralar deneme aşamasında olan meta evreninde varlık gösterme çabalarının birçoğunun elenmesi söz konusu olabilir. Bunların başında gerçek dünyanın kopyasını meta evrenine taşıyarak insanlara, gerçek dünyada başkalarına ait olan yerleri pazarlayan projelerin gelmesi olasıdır. Meta evreninin kuşkusuz özgün ve gerçek dünyanın ötesinde olması beklenmektedir. 
Meta evrenin gelişiminin devam etmesi sonucunda, günümüzde kullanılan internetin işlevselliğinin de değişmesi beklenmektedir. İnternet üzerinde oynanan oyunlardan, sosyal medya mecralarına, günlük hayatın tüm dijital pratiklerinin meta evrenine taşınma ihtimali söz konusudur. İnternetin hali hazırda insanların gerek sosyal gerek iş yaşamlarında vazgeçilmesi güç bir teknoloji olduğu ortadadır. Meta evreniyle birlikte bu teknolojinin kapsamından işlevine kadar tüm özelliklerinin gerçek hayatın dijital yansıması şeklinde yeniden kurgulanması söz konusudur. Bu değişimin beraberinde, dijital moda tasarımcısı, akıllı sözleşme uzmanı, meta evreni tasarımcısı, meta evreni güvenlik uzmanı gibi birçok yeni çalışma alanı açma potansiyelini de barındırmaktadır.

Meta evreninin blokzinciri ile olan bağına Web 3.0 konusundaki beklentiler de eklenince, internetin gelecekteki yapısının bugünkünün çok ötesinde olacağı ihtimali güçlenmektedir. NFT varlıkların sergilenme özelliği, meta evreninin bu varlıkların teşhiri için en ilgi çeken mecraların başında gelmesi, her ikisinin de birbirinden ayrı düşünülememesine neden olmaktadır. Gelecekte meta evreninin de tıpkı NFT'ler gibi blokzinciri üzerine inşa edilme olasılığı, internetin meta evreni başta olmak üzere blokzinciri üzerinde hayat bulacak sayısız merkeziyetsiz uygulamaya ev sahipliği yapma ihtimalini doğurmaktadır. "Decentralized application" (DApp) olarak anılan ve işlemesi için herhangi bir kişi, kurum ya da merkeze ihtiyacı olmayan, blokzinciri ağı üzerinde çalışan merkeziyetsiz uygulamalara ilişkin projelerin sayıları da giderek artmaktadır. Günümüzde deyim yerinde ise interneti domine eden sosyal medya şirketlerinin, üçüncü parti kişi ya da kurumlardan neredeyse tamamen bağımsız olarak varlık göstermesi beklenen merkeziyetsiz uygulamalar karşısında eriyerek tarihe karışma ihtimalleri bulunmaktadır. Blokzinciri ağı temelli Web 3.0 üzerinde çalışması için geliştirilen bu merkeziyetsiz uygulamaların, gelecekte Instagram, Twitter, Facebook, YouTube ve Whatsapp gibi Web 2.0 uygulamalarının yerine geçmesi beklenmektedir.

Milyarlarca dolarlık reklam gelirine sahip olan Web 2.0 uygulamalarının Web 3.0 ürünü olması beklenen merkeziyetsiz uygulamalar karşısında, bugünden çeşitli önlemler aldıkları Facebook'un adının değişmesi ve kripto para projesi yürütmesi gibi çalışmalarla gün yüzüne çıkmaktadır. Merkeziyetsiz internetin merkeziyetsiz uygulamalarının reklam veren ve hedef kitle arasındaki aracı yapıları ortadan kaldırma ihtimali, söz konusu önlemlere her geçen gün bir yenisinin ekleneceğinin de habercisidir. Tüm bunların yanı sıra internetin blokzinciri ile bütünleşmesi durumu, devletlerin de bu muhtemel değişim konusunda teknik ve yasal alt yapılar hazırlamalarını gerektirecektir. 


\section{KAYNAKÇA}

Akleylek, S. \& Seyhan, K. (2018). Blok Zinciri Bileşenleri ve Uygulamaları Üzerine Bir Derleme. Informasiya Tahlükasizliyinin Aktual Multidissiplinar Elmi-Praktiki Problemlari, IV Respublika Konfransı Bildiri Kitabı.

Allan, Roy A. (2001). A History of The Personal Computer: The People And the Technology. Allan Publishing.

Arvas, İbrahim S. (2018). Cumhurbaşkanı Adaylarının Twitter Hesaplarındaki İçeriklerin Türlerine Göre Geri Bildirim Alma Oranları. International Conference on Multidisciplinary Sciences Full Text Book, Strategic Researches Academy.

BBC (Ekim 2021). Facebook Changes its Name to Meta in Major Rebrand. https://www.bbc.com/news/technology-59083601

BBC (Şubat 2021). Bitcoin consumes more electricity than Argentina. https://www.bbc.com/news/technology-56012952

Blokzinciri Teknolojisi Terminoloji Çalışması (2019). Türkiye Bilişim Vakfı. Hukuk. https://bctr.org/dokumanlar/Blokzinciri_Teknoloji_Terminoloji.pdf

Berners-Lee, T. \& Fischetti, M. (2000). Weaving th Web: The Original Design of the World Wide Web by its Invertor. Harper Collins Publishers.

Berners-Lee, T., Hendler, J. \& Lasilla, O. (2001). The Semantic Web: A New Form of Web Content That is Meaningful to Computers Will Unleash a Revolution of New Possibilities. Sicentific American. https://www.scientificamerican.com/article/the-semantic-web/

Binance Academy (Aralık 2018). Blockchain Advantages and Disadvantages. https://academy.binance.com/en/articles/positives-and-negatives-of-blockchain

Çarkacıoğlu, A. (2016). Kripto-Para Bitcoin, Araştırma Raporu. Sermaye Piyasası Kurulu Araştırma Dairesi. https://www.spk.gov.tr/SiteApps/Yayin/YayinGoster/1130

DiNucci, D. (Nisan 1999). Fragmented Future. Print Magazine, 53 (4), 32, 221-222.

Duffy, Clare (Şubat 2021). Facebook's Dream of Creating its Own Global Cryptocurrency Officially Comes to An End. https://edition.cnn.com/2022/02/01/tech/facebook-diem-associationdissolving/index.html

Gatteschi, V., Fabrizio, L., Claudio, D., Chiara, P. \& Victor, S. (2018). To blockchain or not to blockchain: That is the question, IT Professional, 20(2), 62-74. 
Grayscale Research (2021). The Metaverse, Web 3.0 Virtual Cloud Economies. Grayscale. https:/grayscale.com/wpcontent/uploads/2021/11/Grayscale_Metaverse_Report_Nov 2021.pdf

Hoffman, Donna L. (2000). The Revolution Will Not Be Televised: Introduction to the Special Issue on Marketing Science and the Internet. Marketing Science 19(1),1-3.

McLuhan, M. (1962). The Gutenberg Galaxy, The Making of Typographic Man. University of Toronto Press.

Nakamoto, S. (2008). Bitcoin: A Peer-to-Peer Electronic Cash System. https://bitcoin.org/bitcoin.pdf

O'Reilly, T. (2005). What Is Web 2.0, Design Patterns and Business Models for the Next Generation of Software. http://www.oreilly.com/pub/a/web2/archive/what-is-web-20.html

Ross, J (Haziran 2021). The Biggest Companies in the World in 2021, Visiual Capitalist, https://www.visualcapitalist.com/the-biggest-companies-in-the-world-in-2021/

Stephenson, N. (1992). Snow Crash. Bantam Spectra Books.

Tilagal (Mayıs 2021). Sanatta Dijital Dönüşüm: Kripto Sanat NFT. http://www.tilegal.com/Assets/Upload/nft.pdf

Tim Berners-Lee (2021 Ekim 9). MIT Üniversitesi Akademik Personel Profil Sayfası. https://www.csail.mit.edu/person/tim-berners-lee

The First Web 2.0 Conference. (2004, Ekim 7). The First Web 2.0 Conference. https://www.historyofinformation.com/detail.php?id=1654

Ünal, F., (2015) Büyük Veri ve Semantik, Abaküs Kitap Yayın Pazarlama, İstanbul

Wüst, K. \& Gervais, A., (2017). Do You Need a Blockchain?. In Proceedings of the 2018 Crypto Valley Conference on Blockchain Technology (CVCBT), Zug, 45-54. 